\title{
I feira de ciências da cidade de Salvaterra (Pará): um exemplo de educação não formal em ciências naturais
}

\author{
I sciences fair at city of Salvaterra (Pará): an example of non-formal education in natural \\ science
}

\author{
A. N. C. Barbosa ${ }^{1 *}$; R. H. A. Santos ${ }^{1}$; R. F. Souza ${ }^{2}$ \\ ${ }^{1}$ Campus XIX/Salvaterra, Universidade do Estado do Pará, 68860-000, Salvaterra, Pará, Brasil \\ ${ }^{2}$ Departamento de Ciências Naturais/Grupo de Pesquisa em Química, Ensino de Química e Meio Ambiente, Campus \\ XIX/Salvaterra, Universidade do Estado do Pará, 68860-000, Salvaterra, Pará, Brasil \\ *ananay39@gmail.com \\ (Recebido em 05 de abril de 2016; aceito em 16 de abril de 2016)
}

\begin{abstract}
No biênio 2014/2015 foi realizado a primeira Feira Municipal de Ciências de Salvaterra que abordou a temática da sustentabilidade socioambiental do Marajó, e como resultado impulsionou a implementação de feiras de ciências nas escolas da educação básica nesta localidade. Além de formação de 20 docentes da UEPA e 19 alunos universitários treinados e capacitados em orientar trabalhos de iniciação cientifica voltados à popularização e divulgação das ciências e em realização de Feiras de Ciências em escolas públicas. A culminância das ações realizadas nas escolas, a execução da Feira Municipal, ocorreu apresentação de trabalhos elaborados e desenvolvidos por alunos e professores do ensino fundamental, médio e técnico. O título do trabalho ganhador do nível de ensino fundamental foi "a implantação da coleta seletiva na comunidade de Passagem Grande como alternativa de fonte de renda e qualidade de vida" e o trabalho ganhador do nível de ensino médio e técnico foi "aproveitamento integral dos alimentos". A realização desse projeto possibilitou criar um importante local de divulgação cientifica, possibilitando compartilhar informações cientificas e tecnológicas com a comunidade escolar da região do Marajó. As ações realizadas durante a execução deste projeto proporcionou formação acadêmica complementar dos discentes, os quais passam a ter a possibilidade de aplicar à sociedade seus conhecimentos e, consequentemente, aprender na prática aquilo que só se aprende em atividades desse cunho.

Palavras-chave: Feira de ciências, Divulgação científica, Salvaterra
\end{abstract}

In 2014/2015 biennium was held the first city fair Sciences at Salvaterra. The event addressed the theme of the social and environmental sustainability of Marajó, and as a result boosted the implementation of science fairs in schools of basic education in this locality. In addition to formation of 20 teachers of the UEPA and 19 university students trained and qualified in guiding work of scientific initiation to popularization and dissemination of science and in science fairs in schools. The culmination of the actions carried out in schools, running the county fair, which took place the presentation of works produced and developed by students and teachers of elementary, middle and technical levels. The title winner of the elementary level was "the implementation of selective waste collection in the community of "Passagem Grande" as an alternative source of income and quality of life" and the work won high school and technical level was "integral utilization of food". The realization of this project made it possible to create a major site of scientific dissemination, providing scientific and technological information sharing with the school community of the region of Marajo. The actions performed during the execution of this project has provided supplementary's education of the students, which have the possibility of applying the knowledge society and, consequently, learn in practice what you learn only in activities of this nature.

Keywords: Science fair, Scientific divulgation, Salvaterra 


\section{INTRODUÇÃO}

A revolução tecnológica fez com que a ciência e a tecnologia se tornassem fundamentais e determinantes para o crescimento de qualquer país. E ainda, fez surgir novos desafios como a proteção ambiental e o desenvolvimento sustentável. Com isso temas como lixo, poluição do ar e da água passaram ser problemas de todos, não apenas dos ambientalistas. Por conseguinte, todos os cidadãos deveriam influenciar conscientemente os rumos das soluções técnicocientificas e a incorporação destas ao nosso cotidiano [1]. Assim, se faz necessário que os discentes sejam cidadãos conscientes e hábeis para agir em tais problemáticas na sua comunidade e no mundo. Desse modo, é preciso um currículo que vá além dos conteúdos das disciplinas e que estimule um pensamento crítico e reflexivo para se posicionar diante dos problemas de sua realidade.

As feiras de ciências como estratégia de ensino são capazes de fazer com que o aluno, possa desenvolver uma investigação científica e elaborar conclusões a partir dos resultados obtidos por experimentação e socializar estas informações com a comunidade, possibilitando um intercâmbio de informações, favorecendo um conjunto de experiências interdisciplinares, complementando o ensino formal [2]. As feiras de ciências também permitem os alunos a desenvolver sua curiosidade e a pesquisar soluções para resolver os problemas reais da sua comunidade, além de exigir tomada de decisão e outras contribuições para sua formação profissional [3].

O território brasileiro tem grandes dimensões, fato que dificulta à implantação de políticas nacionais de desenvolvimento científico e tecnológico que também atendam às necessidades regionais. Nessa conjuntura, a realização de feira de ciências é instrumento acessível no Brasil inteiro. Nosso país deve preocupar-se em popularizar a ciência na mesma velocidade do crescimento da produção científica, no intuito de conscientizar as pessoas sobre os impactos da ciência e da tecnologia em suas vidas. Consciência essa que vá além dos benefícios ou malefícios dos produtos tecnocientíficos, esta conscientização deve contribuir para a cultura científica de um cidadão, que seja capaz de tomar decisões por conta própria e cobrar o acesso às melhorias prometidas e possíveis com a ciência aplicada [4].

A difusão do conhecimento tecnocientífico é um instrumento de inclusão social e melhoria da qualidade de vida, considerando o quanto o acesso à educação reflete na condição econômica dos cidadãos. A região de Integração do Marajó apresenta baixos índices de desenvolvimento econômico e sociais. Todos os seus municípios, com exceção de Bagre, apresentam taxas de Gini superiores a meio. Salvaterra apresentou em 2010, taxa de 0,57 [5]. Neste contexto, idealizou-se fomentar a realização da primeira feira de ciências da cidade de Salvaterra- FCCS, com a temática da sustentabilidade socioambiental do Marajó.

As feiras de ciências não podem ser apenas exposição de experimentos científicos copiados de livro ou da internet ou mesmo propostos pelo professor. Uma vez que a iniciação cientifica, um dos principais objetivos deste tipo de evento; concretiza-se pela exploração da curiosidade e interesse dos alunos, pela aquisição de uma formação de hábitos, habilidades e atitudes inerentes ao pensamento científico. Pela iniciação científica deverá ser adquirida a compreensão da Ciência como a relação entre as coisas do cotidiano e os fenômenos da natureza, em um processo continuo e permanente [6].

Ao longo da realização de feiras de ciências, seja no início, desenvolvimento e apresentação dos trabalhos há um longo caminho a ser percorrido, comumente envolvendo grande parte da comunidade. Nesse cenário o professor é uma das principais forças motoras, pois este profissional orienta e por fim conduz a iniciação científica dos alunos, momento no qual, geralmente, destaca-se a questão da formação continuada. Por vezes estes professores só possuem a formação inicial, então como é que o professor poderá ensinar seu aluno a pesquisar se ele mesmo não for pesquisador/investigador?

O professor precisa de formação continuada que inclua a sua área de conhecimento específico, a pedagógica e a dimensão político-social. Formação que o incentive a trabalhar em grupo, trocando ideias com outros profissionais de educação e a desenvolver seu trabalho na condição de mediador de aprendizagens que construa parcerias com seus alunos visando à educação e formação profissional [7]. 
A formação continuada referida é o processo pelo qual os professores no desempenho de suas atividades profissionais, através de palestras, seminários, cursos, oficinas e outras formações quaisquer busca adequar sua formação as exigências de sua prática educativa [8]. Na consecução deste tipo de evento que tenha como um dos seus objetivos a iniciação científica, é indispensável estabelecer parceria entre instituições federais, estaduais e municipais visando à formação continuada dos professores, como um objetivo específico necessário para a ocorrência da feira municipal.

A execução de feiras de ciências permite à implementação de estratégias de ensinoaprendizagem para a elaboração e execução de projetos de pesquisa técnico-científica que permitem o desenvolvimento de competências e habilidades nos estudantes do ensino fundamental, médio e técnico para a aplicabilidade do conhecimento científico como um instrumento de melhoria na qualidade da vida social. Esta iniciativa de adotar a feira de ciências como um espaço não formal de ensino pode consolidar uma ação educativa contextualizada; capaz de promover o surgimento de atitude responsável e comprometida da comunidade escolar com as questões ecológicas locais.

Considerando o exposto, objetivou-se realizar a I Feira de Ciências da Cidade de SalvaterraIFCCS, com o intuito de despertar o interesse da comunidade escolar do ensino fundamental, médio e técnico pela construção do conhecimento científico, promovendo, por meio de orientações, reflexões, discussões e socialização de informações e experiências, a construção e a disseminação de saberes e fazeres favoráveis à popularização das ciências no contexto escolar.

\section{MATERIAL E MÉTODOS}

As ações deste projeto foram realizadas no período de dois anos (2014/2015), durante o qual foi promovida a realização de um conjunto de atividades, pertinentes ao projeto e interligadas entre si, tais como: palestras, seminário, oficinas de elaboração e execução de projetos de investigação científica destinadas a professores e alunos das escolas participantes e discentes dos cursos de graduação ofertados pela Universidade do Estado do Pará (UEPA)/Campus XIX/Salvaterra, com a perspectiva de assegurar por meio de um processo interativo, participativo e crítico a troca de conhecimentos, vivências e experiências indispensáveis à inserção destes sujeitos em atividades que estimulassem a iniciação científica nas escolas.

Ao longo do biênio 2014/2015, foram desenvolvidas as seguintes etapas: 1. Organização e planejamento das atividades desenvolvidas e formação das equipes de trabalho com divisão de tarefas; 2. Ações de fomento e divulgação do evento; 3. Ações para realização das Feiras de Ciências nas escolas; 4. Ações desenvolvidas durante a realização da I FCCS.

No dia 27 de novembro de 2015 na quadra esportiva da Escola Estadual de Ensino Médio "Salomão Matos" ocorreu a culminância do evento no horário de 09:00 às 12:00 e de 14:00 às 17:00 horas.

Durante o evento ocorreu:

1. Apresentação/exposição dos trabalhos com características técnico-científicas de abordagem da temática concernente à sustentabilidade socioambiental do Marajó que foram elaborados e desenvolvidos por alunos e professores do ensino fundamental, médio e técnico do município com o apoio dos graduandos dos cursos de graduação existentes no Campus XIX/Salvaterra

2. Apresentação/exposição e mostras de atividades tecnológicas, educativas e informativas apresentadas por professores, pesquisadores e outros profissionais pertencentes ao quadro institucional da UEPA, como também de outras instituições congêneres, conforme identificação a seguir: Ciência itinerante do Centro de Ciências e Planetário do Pará; exposição da Coleção Zoológica da UEPA; exposição de mostras do Herbário da UEPA; exposição de peças da Marioteca itinerante da UEPA; exposição de materiais paradidáticos do Campus da IFPA Tucuruí; apresentação dos trabalhos desenvolvidos na região do Marajó pelo "Projeto Bicho D'água: Conservação Socioambiental”; disseminação de ações informativas sobre prevenções de doenças e boas práticas sobre manuseios de alimentos da Secretaria de Saúde do município e 
exposição de trabalhos acadêmicos apresentados pelos graduandos dos cursos de Ciências Naturais e Tecnologia de Alimentos do Campus de Salvaterra.

3.Visitação do público a Feira municipal de ciências. Este momento representou o ponto culminante do evento que reuniu um público de aproximadamente 1.000 pessoas entre alunos, professores, diretores, técnicos e demais profissionais das redes municipal e estadual de ensino, Secretário municipal de educação, autoridades políticas municipais, pais de alunos, docentes, discentes e pesquisadores da educação superior, representantes de entidades governamentais e não governamentais e a comunidade geral. O público presente ao visitar os estandes teve a oportunidade de conhecer melhor os trabalhos selecionados que foram apresentados e estavam concorrendo à premiação nas categorias de ensino fundamental e médio/técnico. Também foi possível conhecer, durante as visitações das mostras e trabalhos expostos, um pouco mais sobre outras atividades desenvolvidas pela UEPA em outras localidades e por outras instituições de educação superior, assim como foram visitados e conhecidos projetos e programas desenvolvidos por entidades governamentais e não governamentais atuantes na região. Além disso, foram disponibilizadas informações sobre os cursos oferecidos pela UEPA, em especial os cursos ofertados no Marajó e sua contribuição para a região, bem como foi possível conhecer algumas atividades, projetos e programas nas áreas de ensino, pesquisa e extensão desenvolvidos no Campus de Salvaterra que foram apresentados pelos graduandos do Campus.

4. Avaliação dos trabalhos apresentados nas categorias ensino fundamental e médio/técnico. De acordo com o regulamento, as comissões julgadoras foram compostas por professores/pesquisadores da universidade e por avaliadores convidados que atuam nas áreas relacionadas à Ciência, Tecnologia e Educação, com reconhecida experiência profissional. Dessa forma, formaram-se duas comissões julgadoras para avaliação dos trabalhos apresentados, sendo que uma equipe de avaliadores foi formada por 05 professores que avaliaram os trabalhos que estavam concorrendo na categoria de ensino fundamental e outra equipe de avaliadores foi composta por 04 professores que avaliaram os trabalhos concorrentes na categoria ensino médio/técnico. Seguindo o regulamento, no momento que estavam percorrendo os estandes, os professores das comissões julgadoras dos trabalhos não estavam identificados.

A avaliação dos trabalhos apresentados durante a FCCS ocorreu da seguinte forma: os membros das comissões julgadoras, após a leitura do resumo do pôster e observação in loco da exposição do trabalho, atribuíram notas de 0 a 10 para cada um dos itens considerados na ficha de avaliação. Sendo que os seguintes aspectos foram observados durante a avaliação dos trabalhos: conhecimento científico; domínio do conteúdo; criatividade e inovação; participação dos componentes da equipe; qualidade da apresentação; qualidade do trabalho; organização geral (inclusive a limpeza e a organização do local da exposição).

Ao final do processo de avaliação as comissões julgadoras realizaram por meio da ficha de avaliação a seleção dos dois melhores trabalhos nas categorias ensino fundamental e médio/técnico para receberem premiação.

- Cerimônia de premiação dos trabalhos apresentados. Todos os participantes que apresentaram trabalhos de cunho científico durante a I FCCS fizeram jus a um certificado de participação no evento. Os discentes do ensino fundamental e médio/técnico autores dos trabalhos apresentados juntamente com seus professores orientadores receberam medalha de participação. E finalmente, os dois primeiros trabalhos de cada nível de ensino avaliados com o maior valor de pontuação e também suas respectivas escolas foram contemplados com premiação especial contendo kits educativos de incentivo à investigação científica.

\section{RESULTADOS E DISCUSSÃO}

A realização deste evento envolveu professores e alunos no desenvolvimento de atividades e ações que foram planejadas e organizadas com a perspectiva de estimular a iniciação científica nas escolas de ensino fundamental, médio e técnico da educação básica do município de Salvaterra, na tentativa de instigá-los a apropriar-se de informações e conhecimentos que 
pudessem instrumentalizá-los para o desenvolvimento de um trabalho pedagógico conjunto que viesse estimular o desenvolvimento da pesquisa e investigação científica no contexto escolar.

Dessa forma, foi possível observar o impacto positivo gerado pelo conjunto de ações realizadas nas escolas envolvidas na elaboração, organização, execução e avaliação de suas feiras de ciências, tendo como ponto focal a vivência do processo de apreensão do método científico para a produção de conhecimento e o desenvolvimento de competências e habilidades dos sujeitos envolvidos nesse processo para a aplicabilidade do conhecimento científico como um instrumento de melhoria na qualidade da vida social.

O desenvolvimento das atividades realizadas para a execução da feira de ciências auxiliou no preparo e instrumentalização de 18 professores da educação básica, 19 estudantes universitários dos cursos de graduação ofertados pelo Campus de Salvaterra, 20 docentes e pesquisadores da educação superior para um maior envolvimento, participação, troca de ideias e experiências que lhes permitissem acesso as informações atualizadas na sua área de atuação profissional ou a ela relacionadas.

Observou-se que a primeira edição da FCCS contou com a participação de escolas públicas de ensino fundamental, médio e técnico. Foram inscritos 21 trabalhos, sendo 13 do ensino fundamental (Quadro 1) e 8 do ensino médio ou técnico (Quadro 2).

Quadro 1 - Relação dos trabalhos inscritos pelos alunos do Ensino Fundamental na I FCCS, no ano de 2015

\begin{tabular}{|c|c|}
\hline Título do projeto & Escola \\
\hline $\begin{array}{l}\text { O uso de geradores eólicos no município de Salvaterra } \\
\text { como fonte de produção alternativa de energia elétrica. }\end{array}$ & $\begin{array}{l}\text { Escola Municipal de Ensino Fundamental } \\
\text { "Prof. }{ }^{\text {a Oscarina Santos" }}\end{array}$ \\
\hline $\begin{array}{l}\text { Composto orgânico: Uso e benefícios para a } \\
\text { sustentabilidade no município de Salvaterra - Pará. }\end{array}$ & 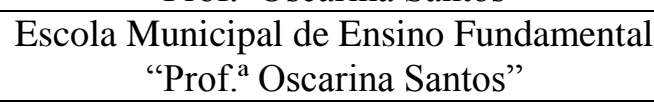 \\
\hline $\begin{array}{c}\text { Análise qualitativa e comparativa da água nos bairros } \\
\text { Paes de Carvalho, Caju e Centro na cidade de } \\
\text { Salvaterra-Pará }\end{array}$ & 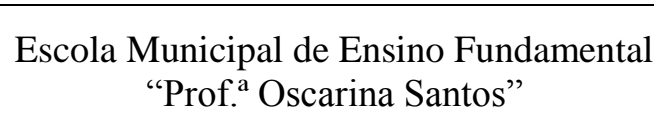 \\
\hline $\begin{array}{c}\text { Utilização de cascas e sementes de vegetais visando a } \\
\text { diminuição do desperdício de resíduos orgânicos e o } \\
\text { enriquecimento nutricional de alimentos. }\end{array}$ & $\begin{array}{l}\text { Escola Municipal de Ensino Infantil e } \\
\text { Fundamental Bahaí }\end{array}$ \\
\hline $\begin{array}{l}\text { A implantação da coleta seletiva na comunidade de } \\
\text { Passagem Grande como alternativa de fonte de renda e } \\
\text { qualidade de vida }\end{array}$ & $\begin{array}{l}\text { Escola Municipal de Ensino Infantil e } \\
\text { Fundamental Marilda Nunes }\end{array}$ \\
\hline Erosão: a ação humana e seus impactos & $\begin{array}{l}\text { Escola Municipal de Ensino Infantil e } \\
\text { Fundamental Marilda Nunes }\end{array}$ \\
\hline $\begin{array}{c}\text { Destino das sacolas plásticas consumidas na } \\
\text { Comunidade de Passagem Grande/Salvaterra-PA }\end{array}$ & $\begin{array}{l}\text { Escola Municipal de Ensino Infantil e } \\
\text { Fundamental Marilda Nunes }\end{array}$ \\
\hline $\begin{array}{l}\text { A importância de conhecer os processos de tratamento } \\
\text { da água consumida no município de Salvaterra por } \\
\text { meio de uma atividade lúdica. }\end{array}$ & $\begin{array}{c}\text { Escola Municipal de Ensino Fundamental } \\
\text { Dom Pedro I }\end{array}$ \\
\hline Horta hidropônica sustentável & $\begin{array}{c}\text { Escola Municipal de Ensino Fundamental } \\
\text { Dom Pedro I }\end{array}$ \\
\hline $\begin{array}{l}\text { A problemática socioambiental do lixo, desenvolvida } \\
\text { com alunos do ensino fundamental e sua transformação } \\
\text { em artigos de decoração. }\end{array}$ & $\begin{array}{c}\text { Escola Municipal de Ensino Fundamental } \\
\text { Dom Pedro I }\end{array}$ \\
\hline $\begin{array}{l}\text { Artesanato em bambu: alternativa de renda para os } \\
\text { alunos das Comunidades remanescentes de } \\
\text { Quilombolas no município de Salvaterra }\end{array}$ & $\begin{array}{l}\text { Escola Municipal de Ensino Fundamental } \\
\text { Quilombola Maria Lúcia Ledo Carvalho }\end{array}$ \\
\hline O uso de resíduos orgânicos no cultivo de hortaliças & $\begin{array}{l}\text { Escola Municipal de Ensino Fundamental } \\
\text { Quilombola Maria Lúcia Ledo Carvalho }\end{array}$ \\
\hline $\begin{array}{l}\text { Transformações de energia: nada se perde tudo se } \\
\text { transforma }\end{array}$ & $\begin{array}{l}\text { Escola Municipal de Ensino Fundamental } \\
\text { Quilombola Maria Lúcia Ledo Carvalho }\end{array}$ \\
\hline
\end{tabular}


Quadro 2 - Relação dos trabalhos inscritos pelos alunos do Ensino Médio ou Técnico na I FCCS, no ano de 2015

\begin{tabular}{|c|c|}
\hline Título do projeto & Escola \\
\hline $\begin{array}{c}\text { Economia - Meio Ambiente: Porque o preço do } \\
\text { pescado é tão caro. }\end{array}$ & $\begin{array}{c}\text { Escola Estadual de Ensino Médio } \\
\text { "Salomão Matos" }\end{array}$ \\
\hline $\begin{array}{c}\text { O aproveitamento de resíduos orgânicos } \\
\text { depositados pela maré nas enseadas das praias de } \\
\text { Salvaterra/PA como adubo para hortaliças e } \\
\text { fruticulturas }\end{array}$ & $\begin{array}{c}\text { Escola Estadual de Ensino Médio } \\
\text { "Salomão Matos" }\end{array}$ \\
\hline $\begin{array}{c}\text { Compostagem Domiciliar } \\
\text { Processo Respiratório }\end{array}$ & $\begin{array}{c}\text { Escola Estadual de Ensino Médio } \\
\text { "Salomão Matos" de Ensino Médio } \\
\text { "Salomão Matos" }\end{array}$ \\
\hline Trator agrícola /florestal & $\begin{array}{c}\text { Escola Estadual de Ensino Médio } \\
\text { "Salomão Matos" }\end{array}$ \\
\hline Aproveitamento Integral dos Alimentos & Escola Tecnológica do Estado do Pará \\
\hline Secretaria sustentável: Uma nova forma de \\
construção & Escola Tecnológica do Estado do Pará \\
\hline Agricultura Orgânica: um olhar para o futuro & Escola Tecnológica do Estado do Pará \\
\hline
\end{tabular}

Analisando os projetos inscritos para a I FCCS pôde-se observar que a temática principal foi a sustentabilidade socioambiental da região, mostrando o interesse de alunos e professores com temas relacionados à temática em questão.

O título do trabalho ganhador do nível de ensino fundamental foi "A implantação da coleta seletiva na comunidade de Passagem Grande como alternativa de fonte de renda e qualidade de vida", esse trabalho foi realizado na comunidade de Passagem Grande/Salvaterra- PA situada na Rodovia PA 154 - km 23. A amostra deste estudo foi constituída de 15 famílias que residem nesta comunidade e apresentou os objetivos de: Diminuir a quantidade de lixo na comunidade; Promover o aparecimento de novos hábitos saudáveis no local, com a prática da coleta seletiva; Fazer com que várias comunidades se espelhem e façam o mesmo.

E o trabalho ganhador do nível de ensino médio foi "Aproveitamento Integral dos Alimentos". Esse estudo abordou que a economia da maioria da população está diretamente ou indiretamente ligada à pesca e ao cultivo de frutas, como o abacaxi. Neste sentido, este trabalho teve como objetivo elaborar produtos, visando o aproveitamento integral dos alimentos, bem como, a valorização de frutas e pescados regionais, destacando a possibilidade da redução do desperdício de alimentos, através do aproveitamento integral dos alimentos.

\section{CONCLUSÃO}

A realização deste projeto contribuiu para a promoção de evento de divulgação científica no contexto escolar, na medida em que a abordagem da temática da sustentabilidade socioambiental do Marajó impulsionou a implementação de feiras de ciências nas escolas da educação básica nesta localidade, despertando o interesse de professores e alunos destes níveis de ensino para a exposição de trabalhos de cunho científico.

Com base nas observações realizadas ao longo do período de execução do projeto, notou-se que a vivência destas novas experiências na produção e socialização de conhecimentos são indispensáveis ao desenvolvimento de novas habilidades e competências profissionais. Observase assim, que a feira de ciência apresentou uma contribuição pertinente para o debate acadêmico na área de formação dos sujeitos envolvidos e para o desenvolvimento regional do Marajó. 


\section{AGRADECIMENTOS}

Ao CNPq, CAPES, SEMED-Salvaterra e à UEPA-Campus XIX, pelo apoio financeiro.

\section{REFERÊNCIAS BIBLIOGRÁFICAS}

1. CNPq -Conselho Nacional de Desenvolvimento Científico e Tecnológico . Por que popularizar? Disponível em: <http://cnpq.br/por-que-popularizar〉. Acesso em: 03, mar, 2016.

2. Pereira AB, Oaigen ER, Hennig G. Feiras de Ciências. Canoas: Ulbra, 2000.

3. Farias LN. Feiras de ciências como oportunidades de (re) construção do conhecimento pela pesquisa. 2006. 84 f. Dissertação (Mestrado) - Universidade Federal do Pará, Núcleo Pedagógico de Apoio ao Desenvolvimento Científico, Belém, 2006. Programa de Pós-Graduação em Educação em Ciências e Matemáticas.

4. Acântara MM. Popularização do conhecimento e inclusão social: uma análise das políticas de educação, ciência e tecnologia do Governo lula e sua aplicação na bahia. In: Anais do XI Congresso Luso Afro Brasileiro de Ciências Sociais: Diversidades e (Des)igualdade. Salvador, Ba: Universidad Federal da Bahia - UFBA, 2011.

5. IDESP- Instituto de Desenvolvimento Econômico, Social e Ambiental do Pará Indicadores de qualidade ambiental dos municípios da região de integração do Marajó, Belém: IDESP, 2012

6. Bernad T, Oaigen ER, Souza CA. Avaliação do evento feiras de ciências: aspectos científicos, educacionais, socioculturais e ambientais. Revista Destaques Acadêmicos - Feira de Ciências, Lajeado: Univates, 2013. Edição Especial, p. 85-94. Disponível em: $<$ http://www.univates.br/revistas/index.php/destaques/article/viewFile/714/401>. Acesso em: 03, mar, 2016.

7. Masetto MT, Zukowsky-Tavares C. Formação de professores para currículos inovadores no ensino superior: um estudo num curso de direito.Revista e-Curriculum,São Paulo: PUC-SP, 2015,jan./mar; 13 (01):05 - 27.

8. Matos AF. A formação continuada de professores auxiliando na construção de projetos científicos para feiras de ciências. Dissertação (Mestrado) - Centro Universitário Univates, Lajeado, 2012.Programa De Pós-Graduação Stricto Sensu Mestrado Profissional Em Ensino De Ciências Exatas. Disponível em: <https://www.univates.br/bdu/bitstream/10737/718/1/2014AldinelleFontenelledeMatos.pdf>. Acesso em: 03, mar, 2016. 